REFERENCES AND/OR ACKNOWLEDGEMENTS

No conflict of interest.

\section{CPS-173 ROLE OF THE PHARMACIST IN THE MULTIDISCIPLINARY MANAGEMENT OF OSTEOMYELITIS: FROM MEDICATION RECONCILIATION TO SUPPORT IN CLINICAL DECISION MAKING}

P Gendre*, P Nizet, S Cesbron, J Mocquard, JF Huon, N Serandour, E Corbineau. University Hospital, Pharmacy, Nantes, France

10.1136/ejhpharm-2020-eahpconf.274

Background and importance Since 2015, a pharmacist/resident duo has been conducting drug reconciliation and medication review in the orthopaedic surgery department. They participate in multidisciplinary team (MDT) meetings to discuss patient with osteomyelitis. These clinical case conferences take place every week to determine the most suitable surgical and medical treatments for individual patients.

Aim and objectives The objective of this study was to assess the impact of the pharmacist's involvement in the MDT meetings on the medical management of patients with osteomyelitis. Material and methods A prospective study was conducted on all pharmaceutical recommendations (PRs) made during the MDT meetings. The data collection period was from June to September 2019. All patients had their medications reconciled previously. We used the drug related problem classification system $(\mathrm{DRP})^{1}$ to rate the PRs and to identify the problems, causes, types and outcomes of these interventions.

Results Of the 17 MDT meetings, 220 patient records were reviewed and 24 PRs were identified. The pharmacist provided information about the patient, along with treatment and recommendations in $38 \%$ of cases (renal function, galenic alternatives, previous prescriptions, availability and cost of the drug). For $62 \%$ of patients, this information changed the therapeutic decision: choice of antibiotic (33\%), potential interactions with long term medications (29\%), need to add a drug $(12.5 \%)$ and optimal dosing for $8 \%$ of cases (subtherapeutic in $4 \%$, overdosing in 4\%). A large majority (95.8\%) of the recommendations were accepted by the prescribers. The most common class of medication was systemic antibiotics (88\%).

Conclusion and relevance The work of medication reconciliation and checking prescriptions was carried out by the pharmacist in the orthopaedic department and this allowed better understanding of the patient and their medication. By participating in MDT meetings, the pharmacist can communicate directly with the prescriber and contribute to clinical decision making regarding anti-infective medications. The clinical pharmacist provided a comprehensive review and therefore played a major role in the medical management of patients with osteomyelitis.

\section{REFERENCES AND/OR ACKNOWLEDGEMENTS}

https://www.pcne.org/upload/files/334_PCNE_classification_V9-0.pdf

No conflict of interest.

\section{CPS-174 FACILITATORS AND BARRIERS TO PERFORMING COMPREHENSIVE MEDICATION REVIEWS AND FOLLOW-UP IN OLDER HOSPITALISED PATIENTS BY MULTIPROFESSIONAL WARD TEAMS INCLUDING A CLINICAL PHARMACIST}

1,2T Kempen, ${ }^{1} \mathrm{~A}$ Kälvemark, ${ }^{3} \mathrm{M}$ Sawires, ${ }^{4} \mathrm{D}$ Stewart, ${ }^{1,3} \mathrm{U}$ Gillespie*. ${ }^{1}$ Uppsala University Hospital, Hospital Pharmacy Department, Uppsala, Sweden; '2Uppsala University, Department of Medical Sciences, Uppsala, Sweden; ${ }^{3}$ Uppsala University, Department of Pharmaceutical Biosciences, Uppsala, Sweden; ${ }^{4}$ Qatar University, Qatar University Health College of Pharmacy, Doha, Qatar

10.1136/ejhpharm-2020-eahpconf.275

Background and importance There is a lack of knowledge about factors that influence the performance of comprehensive medication reviews (CMRs) and post-discharge followup by multiprofessional ward teams including a clinical pharmacist. A better understanding of these factors is needed to support implementation and sustainability of CMRs or similar services by clinical pharmacists in hospital practice.

Aim and objectives This study aimed to explore the facilitators and barriers to performing CMRs and post-discharge followup in older hospitalised patients.

Material and methods Physicians and clinical pharmacists were recruited from an ongoing trial at eight internal medicine or geriatric wards in four hospitals in Sweden. Semistructured interviews were conducted with 16 physicians and 7 pharmacists. Interview topics were: working processes, resources, competences, medication related problems, intervention effects and collaboration. The interviews were audio recorded, transcribed verbatim and thematically analysed using the Consolidated Framework for Implementation Research (CFIR). Identified subthemes were categorised as facilitators or barriers and grouped into overarching main themes.

Results In total, 24 facilitators and 25 barriers were identified across all CFIR domains and grouped into six main themes: (a) CMRs and follow-up are needed, but not in all patients; (b) there is a general belief in positive effects; (c) lack of resources is an issue, although the performance of CMRs may save time; (d) pharmacists' knowledge and skills are valuable, but they need more clinical competence; (e) compatibility with hospital practice is challenging, and roles and responsibilities are unclear; and (f) personal contact on the ward is essential for physician-pharmacist collaboration.

Conclusion and relevance Multiple facilitators and barriers for performing CMRs and post-discharge follow-up in older hospitalised patients exist. These factors should be addressed in future initiatives with similar interventions by multiprofessional teams including a clinical pharmacist to ensure successful implementation and sustainability in hospital practice.

\section{REFERENCES AND/OR ACKNOWLEDGEMENTS}

We would like to thank all physicians and pharmacists who participated in this study.

No conflict of interest. 